\title{
Co-existence of NDM-1 and OXA-48 genes in Carbapenem Resistant Klebsiella pneumoniae clinical isolates in Kafrelsheikh, Egypt
}

\author{
Ramadan Ahmed El-Domany ${ }^{1}$, Tarek El-Banna ${ }^{2}$, Fatma Sonbol ${ }^{3}$, Samar Hamed Abu-Sayedahmed ${ }^{4}$
}

1. Department of Microbiology and Immunology, Faculty of Pharmacy, Kafrelsheikh University, Kafrelsheikh, Egypt. E-mail: ramadaneldomany@yahoo.com

2. Department of Pharmaceutical Microbiology, Faculty of Pharmacy, Tanta University, Tanta, Egypt.

E-mail: t_elbanna@yahoo.com

3. Department of Pharmaceutical Microbiology, Faculty of Pharmacy, Tanta University, Tanta, Egypt.

E-mail: f_sonbol@yahoo.com

4. Department of Microbiology and Immunology, Faculty of Pharmacy, Kafrelsheikh University, Kafrelsheikh, Egypt. E-mail: samarhamed580@yahoo.com

\begin{abstract}
Background: The noteworthy spread of carbapenem-resistant K. pneumoniae (CR-KP) isolates represents a significant safety threat.

Objective: Determination of the carbapenemase genes incidence among CR-KP clinical isolates in Kafrelsheikh, Egypt.

Methods: A total of $230 \mathrm{~K}$. pneumoniae isolates were recovered from four hospitals in Kafrelsheikh, Egypt. Susceptibility testing was conducted using Kirby-Bauer method and automated-Vitek2 system. CR-KP isolates were tested using modified Hodge test (MHT) and combined disk synergy test. PCR and DNA sequencing were conducted for CR-KP isolates to recognize the included carbapenemase-genes.

Results: Out of $230 \mathrm{~K}$. pneumoniae isolates, 50 isolates presented resistance to carbapenem (meropenem). All 50 CR-KP isolates were multidrug-resistant (MDR). Genes like blaNDM-1 and blaOXA-48 were the only detected genes among CR-KP with an incidence of $70.0 \%$ and $52.0 \%$, respectively. Up to $74.0 \%$ of the tested isolates carried at least one of the two recorded genes, among them $48.0 \%$ co-harbored both blaNDM-1 and blaOXA-48 genes. The accession-numbers of sequenced blaNDM-1 and blaOXA-48 genes were MG594615 and MG594616, respectively.

Conclusion: This study reported a high incidence of MDR profile with the emergence of blaNDM-1 and blaOXA-48 genes co-existence in CR-KP isolates in Kafrelsheikh, Egypt. Hence, more restrictions should be applied against the spread of such serious pathogens.
\end{abstract}

Keywords: Klebsiella pneumoniae, Egypt, carbapenem resistance, MDR, PCR, blaNDM-1, blaOXA-48, sequencing. DOI: https://dx.doi.org/10.4314/ahs.v21i2.2

Cite as: El-Domany RA, El-Banna T, Sonbol F, Abu-Sayedabmed SH. Co-existence of NDM-1 and OXA-48 genes in Carbapenem Resistant Klebsiella pneumoniae clinical isolates in Kafrelsheikh, Egypt. Afri Health Sci. 2021;21(2). 489-496. https:// dx.doi.org/10.4314/ahs.v21i2.2

\section{Introduction}

Klebsiella pneumoniae (K. pneumoniae) is a member in Enterobacteriaceae family causing serious opportunistic hospital and community-associated infections ${ }^{1-3}$. It is known as one of the most common MDR pathogens showing re-

\section{Corresponding author:}

Samar Hamed Abu-Sayedahmed,

Department of Microbiology and Immunology

Faculty of Pharmacy, Kafrelsheikh University

Post Box 3356

Kafrelsheikh 3356

Kafrelsheikh, Egypt

Telephone number: +2-0-1010369468

E-mail: samarhamed580@yahoo.com sistance to different classes of antibiotics additionally with multiple mechanisms of antibiotic resistance due to easily acquisition of drug resistance genes through transferable elements (plasmids and transposons) ${ }^{4-6}$. Moreover, the infections caused by those serious pathogens are often concomitant with prolonged hospitalization and high mortality rates ${ }^{7,8}$.

The significant spread of MDR K. pneumoniae all over the world has led to extensive use of carbapenem as last-resort antibiotics for treating the infections caused by those pathogens. Unfortunately, the emergence of carbapenem resistance among $K$. pneumoniae has been reported all over the world ${ }^{7}$. Among mechanisms of resistance, production of carbapenem hydrolyzing 
enzymes (carbapenemases) is considered as the most common mechanism of carbapenem resistance and a significant cause of worry in the Middle East and worldwide ${ }^{9-13}$.

Carbapenemases are $\beta$-lactamase enzymes belonging to classes A, B, C and D and can be categorized according to the dependency on divalent cations for the activation of the enzyme into metallo-carbapenemases, MBLs, (zinc-dependent class B) and non-metallo-carbapenemases (zinc-independent classes A, C, and D). The most commonly detected carbapenemases in Enterobacteriaceae are KPC (Klebsiella pneumoniae carbapenemase); GES (Guiana extended-spectrum); VIM (Verona integron encoded metallo- $\beta$-lactamase); IMP (imipenemase), NDM (New Delhi metallo- $\beta$-lactamase) and OXA-48 (oxacillinase-48) ${ }^{14}$.

Regarding the remarkable increase in carbapenem resistance among $K$. pneumoniae isolates, the world nowadays is concerned about screening for those carbapenemase- producing strains. In Egypt, there were several studies about carbapenem resistance, however, some information was known about carbapenem resistance in K. pneumoniae from Delta region. Therefore, this study was conducted to determine the incidence of carbapenem resistance-associated genes in CR-KP clinical isolates in Kafrelsheikh city, Egypt.

\section{Material and Methods \\ Bacterial isolates}

A total of 230 non-duplicated K. pneumoniae clinical isolates were recovered from 1005 different clinical samples that were collected during the period from July 2015 to April 2016 from hospitalized patients in different four hospitals in Kafrelsheikh city; Egypt. The $K$. pneumoniae isolates were recovered from urine $(\mathrm{n}=98)$, blood ( $\mathrm{n}=67)$, sputum $(\mathrm{n}=55)$ and wound $(\mathrm{n}=10)$.

\section{Bacterial identification}

The collected isolates were identified according to Collee et al. ${ }^{15}$ using conventional standard biochemical tests including culturing on MacConkey agar, indole test, citrate utilization, urease test, oxidase reaction, methyl red test, and sugar fermentation. Besides, all isolates which were identified as $K$. pneumoniae were confirmed by the automated Vitek2 ${ }^{\circledR}$ compact system (BioMérieux ${ }^{\circledR}$ ). The recovered isolates were stored in $50.0 \%$ glycerol stock at $-80{ }^{\circ} \mathrm{C}$ for further analysis.

\section{Antimicrobial susceptibility testing}

The Kirby-Bauer disk diffusion method was conducted for all $230 \mathrm{~K}$. pneumoniae isolates using Mueller-Hin- ton agar and the results were recorded in accordance with CLSI 201516 guidelines. The used antimicrobial discs (Oxoid; UK) included beta-lactams as ampicillin $(10 \mu \mathrm{g})$, amoxicillin $(10 \mu \mathrm{g})$, amoxicillin/clavulanic acid

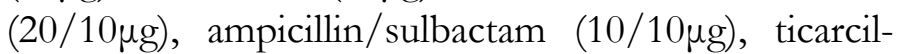
lin/clavulanic acid $(75 / 10 \mu \mathrm{g})$, piperacillin/tazobactam $(100 / 10 \mu \mathrm{g})$, meropenem $(10 \mu \mathrm{g})$, imipenem $(10 \mu \mathrm{g})$, cefoxitin $(30 \mu \mathrm{g})$, cefotetan $(30 \mu \mathrm{g})$, cefazolin $(30 \mu \mathrm{g})$, cefuroxime $(30 \mu \mathrm{g})$, ceftriaxone $(30 \mu \mathrm{g})$, cefotaxime $(30 \mu \mathrm{g})$, ceftazidime $(30 \mu \mathrm{g})$, cefepime $(30 \mu \mathrm{g})$, aztreonam $(30 \mu \mathrm{g})$; aminoglycosides as gentamicin $(10 \mu \mathrm{g})$, tobramycin $(10 \mu \mathrm{g})$, amikacin $(30 \mu \mathrm{g})$ and other antimicrobials including chloramphenicol $(30 \mu \mathrm{g})$, ciprofloxacin $(5 \mu \mathrm{g})$, tetracycline $(30 \mu \mathrm{g})$ and trimethoprim-sulfamethoxazole $(1.25 / 23.75 \mu \mathrm{g})$,. Susceptibility to tigecycline was detected using Vitek2® compact system (BioMérieux $\left.{ }^{\circledR}\right)$. Minimum inhibitory concentrations (MICs) were de-

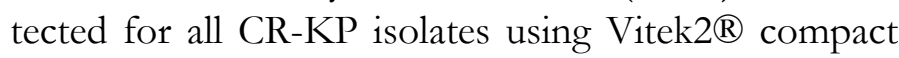
system (BioMérieux $\left.{ }^{\circledR}\right)$. Any isolate would be recorded to have MDR profile if it showed non-susceptibility to $\geq 3$ different antimicrobial classes ${ }^{4}$.

\section{Phenotypic detection of carbapenemases}

All 50 CR-KP isolates were screened for carbapenemases production using $\mathrm{MHT}^{16}$. MBLs were screened in all 50 CR-KP isolates using EDTA combined disc synergy test ${ }^{17,18}$.

\section{Genotypic detection and characterization of car- bapenemase genes by polymerase chain reaction and DNA sequencing}

For genomic DNA extraction, GeneJET Genomic DNA Extraction Kit (Thermo Scientific, USA) was used. For all carbapenem non-susceptible isolates, PCR was performed to detect six of the most frequently widespread carbapenemase genes including blaKPC, blaGES, blaNDM-1, blaVIM, blaIMP and blaOXA-48.

The PCR technique was carried out, using the primers shown in Table 1 , in a final volume of $50 \mu$ consisting of $5 \mu \mathrm{l}$ of DNA template $(5-20 \mathrm{ng} / \mathrm{ml}) ; 25 \mu \mathrm{l}$ of PCR master mix; $2.5 \mu$ l of forward and $2.5 \mu$ l of reverse primer $(0.1-0.5 \mu \mathrm{M})$ and nuclease-free water $(15 \mu \mathrm{l})$ was added to complete the final volume.

The amplification was performed in the thermal cycler (Verti; Applied Biosystem) with initial denaturation for $10 \mathrm{~min}$ at $94^{\circ} \mathrm{C}$. After denaturation, about 36 cycles of amplification were conducted including $30 \mathrm{~s}$ for denaturation at $94^{\circ} \mathrm{C}, 40 \mathrm{~s}$ for annealing at $52^{\circ} \mathrm{C}$, and $50 \mathrm{~s}$ for extension at $72^{\circ} \mathrm{C}$ and the last step was the final elongation for $5 \mathrm{~min}$ at $72^{\circ} \mathrm{C}$. DNA fragments were analyzed 
under UV light after 1 hour of agarose gel electrophoresis $^{19,20}$.

The PCR Purification Kit (\#PP-201S; Jena Bioscience, Germany) was used, according to the manufacturer's protocol, for purification of PCR products. For DNA sequencing, the purified PCR products were sent to
Macrogen Company (South Korea) and sequenced using ABI 3730XL DNA sequencer (Applied Biosystem; USA). The analysis of obtained sequences was performed using the Chromas Lite 2.1 program, BLAST search was used to detect the identity of these sequences against Gen-Bank database and Geneious 4.8.4 software was used for alignments and assembly of the sequences.

Table 1. Nucleotide sequences of PCR oligonucleotide primers

\begin{tabular}{|c|c|c|c|c|}
\hline $\begin{array}{l}\text { Target } \\
\text { gene }\end{array}$ & Primer* & Sequence $\left(5{ }^{`} 3\right.$ ) & $\begin{array}{l}\text { Size } \\
\text { (bp) }\end{array}$ & Reference \\
\hline $\boldsymbol{b} \boldsymbol{b} \boldsymbol{a}_{\mathrm{KPC}}$ & $\begin{array}{l}\text { KPC-F } \\
\text { KPC-R }\end{array}$ & $\begin{array}{l}\text { CGTCTAGTTCTGCTGTCTTG } \\
\text { CTTGTCATCCTTGTTAGGCG }\end{array}$ & 798 & $\begin{array}{c}\text { Poirel, } \\
\text { Laurent, } 2011^{20}\end{array}$ \\
\hline $\boldsymbol{b} \boldsymbol{b} \boldsymbol{a}_{\mathrm{GES}}$ & $\begin{array}{l}\text { GES-F } \\
\text { GES-R }\end{array}$ & $\begin{array}{l}\text { AGTCGGCTAGACCGGAAAG } \\
\text { TTTGTCCGTGCTCAGGAT }\end{array}$ & 399 & $\begin{array}{c}\text { Dallenne, } \\
\text { Caroline, } 2010^{19}\end{array}$ \\
\hline $\boldsymbol{b} \boldsymbol{l} \boldsymbol{a}_{\mathrm{NDM}-1}$ & $\begin{array}{l}\text { NDM-F } \\
\text { NDM-R }\end{array}$ & $\begin{array}{l}\text { GGTTTGGCGATCTGGTTTTC } \\
\text { CGGAATGGCTCATCACGATC }\end{array}$ & 621 & $\begin{array}{c}\text { Poirel, } \\
\text { Laurent,201120 }\end{array}$ \\
\hline $\boldsymbol{b} \boldsymbol{b} \boldsymbol{a}_{\mathrm{VIM}}$ & $\begin{array}{l}\text { VIM-F } \\
\text { VIM-R }\end{array}$ & $\begin{array}{l}\text { GATGGTGTTTGGTCGCATA } \\
\text { CGAATGCGCAGCACCAG }\end{array}$ & 390 & $\begin{array}{c}\text { Poirel, } \\
\text { Laurent,201120 }\end{array}$ \\
\hline $\boldsymbol{b} \boldsymbol{a}_{\mathrm{IMP}}$ & $\begin{array}{l}\text { IMP-F } \\
\text { IMP-R }\end{array}$ & $\begin{array}{l}\text { GGAATAGAGTGGCTTAAYTCTC } \\
\text { GGTTTAAYAAAACAACCACC }\end{array}$ & 232 & $\begin{array}{c}\text { Poirel, } \\
\text { Laurent,201120 }\end{array}$ \\
\hline $\boldsymbol{b l a} \boldsymbol{a}_{\mathrm{OXA}-48}$ & $\begin{array}{l}\text { OXA-F } \\
\text { OXA-R }\end{array}$ & $\begin{array}{l}\text { GCGTGGTTAAGGATGAACAC } \\
\text { CATCAAGTTCAACCCAACCG }\end{array}$ & 438 & $\begin{array}{c}\text { Poirel, } \\
\text { Laurent,2011 }\end{array}$ \\
\hline
\end{tabular}

*F: forward; R: reverse

\section{Results}

The results of the standard biochemical tests, as well as the Vitek2 ${ }^{\circledR}$ compact system revealed the presence of $230 \mathrm{~K}$. pneumoniae isolates among the tested 1005 clinical samples.

The susceptibility testing results of the recovered $230 \mathrm{~K}$. pneumoniae isolates revealed that the incidence of resistance among these isolates ranged from $(0.0 \%)$ for tigecycline to $(98.3 \%)$ for ampicillin. The results indicated that $21.7 \%$ of isolates were carbapenem non-susceptible where 50 isolates were meropenem resistant while for imipenem; 49 isolates were resistant and only one was intermediate resistant to such antimicrobial agent. On the other hand, 175 (76.0\%), 161 (70.0\%) and 138 $(60.0 \%)$ isolates were resistant to ciprofloxacin, amikacin and trimethoprim/sulphamethoxazole respectively. Interestingly, all tested isolates were tigecycline sensitive. Moreover, all detected CR-KP isolates exhibited MDR profile.
Phenotypic detection of carbapenemases production was carried out using MHT and the results revealed that $45(90.0 \%)$ out of 50 tested CR-KP isolates were carbapenemase producers. On the other hand, 33 (66.0\%) out of 50 tested isolates were MBLs producers as detected by combined disk synergy test as shown in Table 2.

All CR-KP isolates were screened by PCR for the detection of blaKPC, blaGES, blaNDM-1, blaVIM, blaIMP and blaOXA-48 genes. The results revealed that blaNDM-1 and blaOXA-48 were the only detected genes where blaNDM-1 was detected in $35(70.0 \%)$ isolates while blaOXA-48 was detected in $26(52.0 \%)$ isolates. Besides, up to $37(74.0 \%)$ isolates carried at least one of the recorded genes where 24 isolates harbored both detected genes while 13 isolates harbored only one of these genes as shown in Table 2. 
Table 2. Phenotypic and genotypic characterizations of tested carbapenem resistant Klebsiella pneumoniae isolates

\begin{tabular}{|c|c|c|c|c|c|}
\hline \multirow{3}{*}{ Isolates } & \multirow{3}{*}{ Sensitivity pattern* } & \multicolumn{4}{|c|}{ Carbapenemases detection } \\
\hline & & \multicolumn{2}{|c|}{ Phenotypic results** } & \multicolumn{2}{|c|}{ Genotypic results } \\
\hline & & MHT & CDST & $b l a_{\mathrm{NDM}-1}$ & $b^{b l a_{\text {OXA-48 }}}$ \\
\hline K1 & $\mathrm{CN}, \mathrm{SXT}, \mathrm{TGC}$ & + & - & - & - \\
\hline K2 & AK, SXT, TGC & + & - & _- & _- \\
\hline $\begin{array}{l}\text { K3, K6, K15, K16, K17, K22, K23, } \\
\text { K24, K27, K32, K34, K35, K38, K42, } \\
\text { K47, K49, K50 }\end{array}$ & SXT, TGC & + & + & $b l a_{\mathrm{NDM}-1}$ & $b l a_{\text {OXA-48 }}$ \\
\hline $\mathrm{K} 4$ & CIP, TGC & + & - & - & $b l a_{\text {OXA- } 48}$ \\
\hline K5 & CIP, TGC & - & - & - & - \\
\hline K7 & CN, AK, CM, TET, CIP, SXT, TGC & - & + & $b l a_{\mathrm{NDM}-1}$ & $b l a_{\text {OXA-48 }}$ \\
\hline K8 & SXT, TGC & + & - & $b l a_{\mathrm{NDM}-1}$ & _- \\
\hline K9 & $\mathrm{CN}, \mathrm{AK}, \mathrm{TGC}$ & + & + & $b l a_{\mathrm{NDM}-1}$ & - \\
\hline $\mathrm{K} 10, \mathrm{~K} 11, \mathrm{~K} 12, \mathrm{~K} 14, \mathrm{~K} 18, \mathrm{~K} 20, \mathrm{~K} 21$ & SXT, TGC & + & - & _- & _- \\
\hline K13 & CN, AK, CM, TET, CIP, TGC & + & - & _- & _- \\
\hline K19 & AK, CM, TET, CIP, SXT, TGC & + & + & $b l a_{\mathrm{NDM}-1}$ & _- \\
\hline K25 & CN, AK, CM, TET, CIP, SXT, TGC & + & - & - & - \\
\hline K26 & AK, TET, CIP, SXT, TGC & - & + & $b l a_{\mathrm{NDM}-1}$ & $b l a_{\text {OXA-48 }}$ \\
\hline $\mathrm{K} 28, \mathrm{~K} 40$ & SXT, TGC & + & + & $b l a_{\mathrm{NDM}-1}$ & - \\
\hline K29 & CN, AK, TET, CIP, TGC & + & + & $b l a_{\mathrm{NDM}-1}$ & - \\
\hline K30 & $\mathrm{AK}, \mathrm{TGC}$ & + & - & - & - \\
\hline K31 & $\mathrm{CN}, \mathrm{AK}, \mathrm{CIP}, \mathrm{TGC}$ & + & + & $b l a_{\mathrm{NDM}-1}$ & $b l a_{\text {OXA-48 }}$ \\
\hline K33 & AK, TET, CIP, TGC & + & + & $b l a_{\mathrm{NDM}-1}$ & $b l a_{\text {OXA-48 }}$ \\
\hline K36 & $\mathrm{TGC}$ & + & - & $b l a_{\mathrm{NDM}-1}$ & $b l a_{\text {OXA- }-48}$ \\
\hline K37, K39 & CIP, TGC & + & + & $b l a_{\mathrm{NDM}-1}$ & - \\
\hline K41 & CN, AK, CM, TET, CIP, TGC & + & + & $b l a_{\mathrm{NDM}-1}$ & - \\
\hline K43 & CIP, TGC & + & + & $b l a_{\mathrm{NDM}-1}$ & $b l a_{\text {OXA- }-48}$ \\
\hline K44 & AK, CIP, SXT, TGC & + & + & $b l a_{\mathrm{NDM}-1}$ & $b l a_{\text {OXA }-48}$ \\
\hline K45 & SXT, TGC & - & - & - & $b l a_{\text {OXA-48 }}$ \\
\hline K46 & AK, SXT, TGC & + & + & $b l a_{\mathrm{NDM}-1}$ & - \\
\hline K48 & AK, CIP, SXT, TGC & - & + & $b l a_{\mathrm{NDM}-1}$ & - \\
\hline
\end{tabular}

\section{Discussion}

The incidence of CR-KP isolates in the Mediterranean area particularly in Egypt represents a serious threat to our hospitals and our community ${ }^{21}$. Therefore, this study was performed to detect the prevalence of carbapenemase genes among $K$. pneumoniae isolates recovered from Egyptian patients in different hospitals in Kafrelsheikh city, Egypt. Our results revealed that the incidence of $K$. pneumoniae isolates among different clinical samples was $22.8 \%$. Susceptibility testing results showed that up to $21.7 \%$ of the tested K. pneumoniae isolates were carbapenem non-susceptible. In agreement with our result, previous studies from Egypt $^{22}$ and different countries ${ }^{23}$ showed comparable results.

The antimicrobial susceptibility testing results of CR$\mathrm{KP}$ isolates showed a high incidence of MDR profile where all tested isolates exhibited multiple antimicrobial resistance, a finding that was also reported in other studies from different countries ${ }^{24-27}$. This finding might reflect unrestricted use of antibiotics in our institute which plays an important role in increasing antibiotic resistance. It worth mentioning that tigecycline was the most active antimicrobial agent where all tested isolates were sensitive to it. This result was confirmed by the results of other studies ${ }^{28-30}$ which also reported 100\% sensitivity of the isolates to tigecycline.

In the present study, the detection of carbapenemase producers was carried out using phenotypic and genotypic methods. Regarding the phenotypic methods, our results revealed that $90.0 \%$ of CR-KP isolates were carbapenemase producers. Moreover, the results revealed that $66.0 \%$ of tested isolates were MBLs producers and this result was comparable $(63.3 \%)$ with that detected by Panchal et al. ${ }^{23}$ but in contrast, lower $(41.9 \%)$ result was detected in another study which was performed in Saudi Arabia ${ }^{31}$. 
The results of genotypic detection methods revealed that $74.0 \%(37 / 50)$ of CR-KP isolates were harboring to carbapenemase genes which was higher than that reported in other Egyptian study ${ }^{32}$ where carbapenemase genes were detected in only $43.0 \% \mathrm{~K}$. pneumoniae isolates. Interestingly, out of the 37 isolates carrying carbapenemase genes that detected by PCR, there were 4 isolates that showed negative results by MHT and this might be explained by weak carbapenemase activity ${ }^{33}$. On the other hand, 13 (26.0\%) of the CR-KP isolates were negative for carbapenemase genes. These isolates may contain other untested carbapenemases or other mechanisms such as extended-spectrum beta-lactamase production coupled with disruption in porin expression may be responsible for their reduced sensitivity to carbapenems ${ }^{34-36}$.

Enterobacteriaceae particularly $K$. pneumoniae producing blaOXA-48 and blaNDM-1 became more prevalent in diverse of the world. In our study, blaOXA-48 and blaNDM-1 were the only detected carbapenemase genes among the tested $K$. pneumoniae isolates. This result was in agreement with other performed studies in Egypt $^{36,37}$; revealing the emergence of the dissemination and rapid spread of these genes through different regions in Egypt. In addition, our result was also reported in other countries ${ }^{38,39}$. Since the first identification of blaNDM-1 from K. pneumoniae retrieved from a Swedish patient of Indian origin traveled to New Delhi, India ${ }^{40}$, worldwide attention was attracted due to the rapid dissemination of the MBLs. In Egypt, the first isolation of blaNDM-1 was reported by Abdelaziz et al. ${ }^{41}$ from ST11 K. pneumoniae isolate that was recovered from a hospitalized patient in an ICU of a cancer hospital in Cairo and after that blaNDM-1 was described in Pseudomonas aeruginosa isolates by Zafer et al..$^{42}$ and in Acinetobacter baumannii isolates by El-Sayed et al. ${ }^{43}$ revealing the spread of blaNDM-1 among Enterobacteriaceae particularly K. pneumoniae isolates ${ }^{44}$. In the present study, blaNDM-1 was identified as a predominant gene and detected in $70.0 \%$ of the tested isolates. This finding was consistent with other studies that recorded the predominance of blaNDM-1 in Egypt and other countries $^{45-49}$.

Regarding the blaOXA-48 gene, it was first detected in $K$. pneumoniae in Turkey ${ }^{50}$ and after that, it spread rapidly throughout the Middle East and then all over the world. In the present study, our results revealed that the second most common carbapenemase gene detected among tested isolates was blaOXA-48 with an incidence of $52.0 \%$. In accordance with our result, Khalifa et al. ${ }^{36}$ and ELMahallawy et al. $^{37}$ from Egypt reported comparable $(49.0 \%$ and $60.0 \%$, respectively) detection rate of blaOXA-48 among carbapenem-resistant isolates. In other Arabian countries, this detected gene was also reported as one of the most detected carbapenemases genes with high incidence such as $66.0 \%$ incidence in Riyadh $^{31}$ and $62.0 \%$ incidence in Lebanon ${ }^{51}$.

Carbapenem-resistant isolates co-producing multiple carbapenemases genes tend to be extremely high resistant and this leads to limitation in treatment options. Our study showed that $48.0 \%$ of tested CR-KP isolates harbored both blaOXA-48 and blaNDM-1, a finding that is considered as the first report of a high incidence of blaOXA-48 and blaNDM-1 co-existence among CR$\mathrm{KP}$ isolates in Egypt. In agreement with our detection rate, Laolerd et al. ${ }^{52}$ reported also $52.0 \%$ as an incidence of isolates that also harbored those both genes. In contrast, neither blaKPC, blaGES, blaVIM nor blaIMP was detected in any of our tested isolates. Other studies also showed very low detection rates of these genes as ELMahallawy et al. ${ }^{37}$ who reported that the incidence of blaIMP was only $1.5 \%$ with the absence of blaKPC and blaVIM among the tested isolates. Additionally, Khalifa et al. ${ }^{36}$ reported a low $(4.6 \%)$ incidence rate of blaVIM with the absence of blaKPC and blaIMP. In accordance with our results, Al-Agamy et al. ${ }^{31}$ also reported the absence of blaIMP, blaVIM, blaGES and blaKPC in the carbapenemase-positive isolates confirming that those genes are not predominate in our geographical region.

\section{Conclusion}

This study reported a high MDR resistance profile among the CR-KP isolates from Kafrelsheikh, Egypt. This high resistance rate in our study may be attributed to the lack of implementation of antimicrobial stewardship program and this reflects also limiting in treatment options. In addition, our study reported the emergence of $\mathrm{K}$. pneumoniae isolates co-harboring blaNDM-1 and blaOXA-48 genes. These findings may be considered as an alarming threat to the healthcare workers in the hospital settings. The results of our study therefore confirmed the need for continually and routinely screening for $\mathrm{K}$. pneumoniae strains especially those producing blaNDM-1 and blaOXA-48 genes to rapidly detect and avoid the dissemination of those strains.

\section{Authors' contributions}

Conception and design: R.A.E.; Acquisition of data/ isolates: S.H.A; Data analysis and interpretation: R.A.E. 
and S.H.A; drafting the article: R.A.E. and S.H.A: Critical revision of the article: R.A.E., F.S., and T.E.; and all authors read and approved the final article.

\section{Disclosure Statement}

No competing financial interests exist.

\section{References}

1. Rice LB. Federal funding for the study of antimicrobial resistance in nosocomial pathogens: no ESKAPE. The Journal of Infectious Diseases. 2008; 197(8): 1079-81.

2. Boucher HW, Talbot GH, Bradley JS, Edwards JE, Gilbert D, Rice LB, et al. Bad bugs, no drugs: no ESKAPE! An update from the Infectious Diseases Society of America. Clinical Infectious Diseases. 2009; 48(1): 1-12. 3. Pendleton JN, Gorman SP, Gilmore BF. Clinical relevance of the ESKAPE pathogens. Expert Review of Anti-infective Therapy. 2013; 11(3): 297-308.

4. Magiorakos AP, Srinivasan A, Carey RB, Carmeli Y, Falagas ME, Giske CG, et al. Multidrug-resistant, extensively drug-resistant and pandrug-resistant bacteria: an international expert proposal for interim standard definitions for acquired resistance. Clinical Microbiology and Infection: The Official Publication of the European Society of Clinical Microbiology and Infectious Diseases. 2012; 18(3): 268-81.

5. Pournaras S, Poulou A, Voulgari E, Vrioni G, Kristo I, Tsakris A. Detection of the new metallo- $\beta$-lactamase VIM-19 along with KPC-2, CMY-2 and CTX-M-15 in Klebsiella pneumoniae. Journal of Antimicrobial Chemotherapy. 2010; 65(8): 1604-7.

6. Navon-Venezia S, Kondratyeva K, Carattoli A. Klebsiella pneumoniae: a major worldwide source and shuttle for antibiotic resistance. FEMS Microbiology Reviews. 2017; 41(3): 252-75.

7. Lee CR, Lee JH, Park KS, Kim YB, Jeong BC, Lee $\mathrm{SH}$. Global Dissemination of Carbapenemase-Producing Klebsiella pneumoniae: Epidemiology, Genetic Context, Treatment Options, and Detection Methods. Front Microbiol. 2016; 7: 895.

8. Calfee DP. Recent advances in the understanding and management of Klebsiella pneumoniae. F1000Research. 2017; 6: 1760.

9. Jeong SH, Lee KM, Lee J, Bae IK, Kim J-S, Kim H-S, et al. Clonal and horizontal spread of the blaOXA-232 gene among Enterobacteriaceae in a Korean hospital. Diagnostic Microbiology and Infectious Disease. 2015; 82(1): 70-2.

10. Chouchani C, Marrakchi R, El Salabi A. Evolution of $\beta$-lactams resistance in Gram-negative bacteria in
Tunisia. Critical reviews in microbiology. 2011; 37(3): 167-77.

11. Hrabák J, Chudáčková E, Papagiannitsis C. Detection of carbapenemases in Enterobacteriaceae: a challenge for diagnostic microbiological laboratories. Clinical Microbiology and Infection. 2014; 20(9): 839-53.

12. Nordmann P, Poirel L. The difficult-to-control spread of carbapenemase producers among Enterobacteriaceae worldwide. Clinical Microbiology and Infection. 2014; 20(9): 821-30.

13. Mathlouthi N, Al-Bayssari C, El Salabi A, Bakour S, Ben Gwierif S, Zorgani AA, et al. Carbapenemases and extended-spectrum beta-lactamases producing Enterobacteriaceae isolated from Tunisian and Libyan hospitals. Journal of Infection in Developing Countries. 2016; 10(7): 718-27.

14. Findlay J, Hopkins KL, Alvarez-Buylla A, Meunier D, Mustafa N, Hill R, et al. Characterization of carbapenemase-producing Enterobacteriaceae in the West Midlands region of England:2007-14. Journal of Antimicrobial and Chemotherapy. 2017; 72: 1054-1062.

15. Collee JG, Mackie TJ, McCartney JE. Mackie \& McCartney practical medical microbiology. New York: Churchill Livingstone; 1996.

16. Patel J, Cockerill F, Bradford P. M100-S25. Performance Standards for Antimicrobial Susceptibility Testing; Twenty-Fifth Informational Supplement. Wayne, PA: Clinical and Laboratory Standards Institute; 2015; 35 (3): 1-16.[Acceso: 19 de junio de 2017].

17. Lee K, Chong Y, Shin H, Kim Y, Yong D, Yum J. Modified Hodge and EDTA-disk synergy tests to screen metallo- $\beta$-lactamase-producing strains of Pseudomonas and Acinetobacter species. Clinical Microbiology and Infection. 2001; 7(2): 88-91.

18. Lee K, Lim Y, Yong D, Yum J, Chong Y. Evaluation of the Hodge test and the imipenem-EDTA double-disk synergy test for differentiating metallo- $\beta$-lactamase-producing isolates of Pseudomonas spp. and Acinetobacter spp. Journal of Clinical Microbiology. 2003; 41(10): 4623-9.

19. Dallenne C, Da Costa A, Decré D, Favier C, Arlet G. Development of a set of multiplex PCR assays for the detection of genes encoding important $\beta$-lactamases in Enterobacteriaceae. Journal of Antimicrobial Chemotherapy. 2010; 65(3): 490-5.

20. Poirel L, Walsh TR, Cuvillier V, Nordmann P. Multiplex PCR for detection of acquired carbapenemase genes. Diagnostic Microbiology and Infectious Disease. 2011; 70(1): 119-23.

21. Girmenia C, Serrao A, Canichella M. Epidemiology 
of carbapenem resistant Klebsiella pneumoniae infections in mediterranean countries. Mediterranean Journal of Hematology and Infectious Diseases. 2016; 8(1).

22. El-Badawy MF, Tawakol WM, El-Far SW, Maghrabi IA, Al-Ghamdi SA, Mansy MS, et al. Molecular Identification of Aminoglycoside-Modifying Enzymes and Plasmid-Mediated Quinolone Resistance Genes among Klebsiella pneumoniae Clinical Isolates Recovered from Egyptian Patients. International Journal of Microbiology. 2017; 2017:8050432.

23. Panchal CA, Oza SS, Mehta SJ. Comparison of four phenotypic methods for detection of metallo-beta-lactamase-producing Gram-negative bacteria in rural teaching hospital. Journal of Laboratory Physicians. 2017; 9(2): 81-3.

24. Aljanaby AAJ, Alhasani AHA. Virulence factors and antibiotic susceptibility patterns of multidrug resistance Klebsiella pneumoniae isolated from different clinical infections. African Journal of Microbiology Research. 2016; 10(22): 829-43.

25. Aljanaby AAJ, Alhasnawi H. Phenotypic and Molecular Characterization of Multidrug Resistant Klebsiella pneumoniae Isolated from Different Clinical Sources in Al-Najaf Province-Iraq. Pakistan Journal of Biological Sciences: PJBS. 2017; 20(5): 217-32.

26. Zheng B, Dai Y, Liu Y, Shi W, Dai E, Han Y, et al. Molecular epidemiology and risk factors of carbapenem-resistant Klebsiella pneumoniae infections in Eastern China. Frontiers in Microbiology. 2017; 8: 1061.

27. Saadatian Farivar A, Nowroozi J, Eslami G, Sabokbar A. RAPD PCR Profile, Antibiotic Resistance, Prevalence of armA Gene, and Detection of KPC Enzyme in Klebsiella pneumoniae Isolates. The Canadian Journal of Infectious Diseases \& Medical Microbiology = Journal Canadien des Maladies Infectienses et de la Microbiologie Medicale. 2018; 2018: 6183162.

28. Gamal D, Fernandez-Martinez M, Salem D, El-Defrawy I, Montes LA, Ocampo-Sosa AA, et al. Carbapenem-resistant Klebsiella pneumoniae isolates from Egypt containing blaNDM-1 on IncR plasmids and its association with $\mathrm{rmtF}$. International Journal of Infectious Diseases: IJID: official publication of the International Society for Infectious Diseases. 2016; 43: 17-20.

29. Mesbah MR, Zaki MES, Alsayed MAL. Multiplex Polymerase Chain Reaction for Klebsiella pneumoniae Metallo- $\beta$-lactamase Causing Neonatal Sepsis in Mansoura Children University Hospital in Egypt. International Journal of Current Microbiology and Applied Scinces. 2016; 5(3): 194-205.

30. Aqel AA, Giakkoupi P, Alzoubi H, Masalha I, Ellington MJ, Vatopoulos A. Detection of OXA-48-like and NDM carbapenemases producing Klebsiella pneumoniae in Jordan: A pilot study. Journal of Infection and Public Health. 2017; 10(2): 150-5.

31. Al-Agamy MH, Aljallal A, Radwan HH, Shibl AM. Characterization of carbapenemases, ESBLs, and plasmid-mediated quinolone determinants in carbapenem-insensitive Escherichia coli and Klebsiella pneumoniae in Riyadh hospitals. Journal of Infection and Public Health. 2018; 11(1): 64-8.

32. Hamdy Mohammed el S, Elsadek Fakhr A, Mohammed El Sayed H, Al Johery SA, Abdel Ghani Hassanein W. Spread of TEM, VIM, SHV, and CTX-M beta-Lactamases in Imipenem-Resistant Gram-Negative Bacilli Isolated from Egyptian Hospitals. International Journal of Microbiology. 2016; 2016: 8382605.

33. Miriagou V, Cornaglia G, Edelstein M, Galani I, Giske CG, Gniadkowski M, et al. Acquired carbapenemases in Gram-negative bacterial pathogens: detection and surveillance issues. Clinical Microbiology and Infection: The Official Publication of the European Society of Clinical Microbiology and Infectious Diseases. 2010; 16(2): 112-22.

34. Memish ZA, Assiri A, Almasri M, Roshdy H, Hathout $\mathrm{H}$, Kaase $\mathrm{M}$, et al. Molecular characterization of carbapenemase production among gram-negative bacteria in saudi arabia. Microbial Drug Resistance. 2015; 21(3): 307-14.

35. El-Kholy AA, Elanany MG, Sherif MM, Gad MA. High Prevalence of VIM, KPC, and NDM Expression among Surgical Site Infection Pathogens in Patients Having Emergency Surgery. Surgical Infections. 2018; 19(6): 629-33.

36. Khalifa HO, Soliman AM, Ahmed AM, Shimamoto T, Hara T, Ikeda M, et al. High Carbapenem Resistance in Clinical Gram-Negative Pathogens Isolated in Egypt. Microbial Drug Resistance. 2017; 23(7): 838-44.

37. ElMahallawy HA, Zafer MM, Amin MA, Ragab MM, Al-Agamy MH. Spread of carbapenem resistant Enterobacteriaceae at tertiary care cancer hospital in Egypt. Infectious Diseases. 2018; 50(7): 560-4.

38. Osei Sekyere J, Govinden U, Bester LA, Essack SY. Colistin and tigecycline resistance in carbapenemase-producing Gram-negative bacteria: emerging resistance mechanisms and detection methods. Journal of Applied Microbiology. 2016; 121(3): 601-17.

39. Zeinab J, Ali HA, Mehri H, Jalil K-Y, Sirous J, Fereshteh J, et al. Molecular Epidemiology and Drug Resistance Pattern of Carbapenem-Resistant Klebsiella pneumoniae Isolates from Iran. Microbial Drug Resistance. 2019; 25(3): 336-43.

40. Yong D, Toleman MA, Giske CG, Cho HS, Sundman $\mathrm{K}$, Lee $\mathrm{K}$, et al. Characterization of a new met- 
allo- $\beta$-lactamase gene, blaNDM-1, and a novel erythromycin esterase gene carried on a unique genetic structure in Klebsiella pneumoniae sequence type 14 from India. Antimicrobial Agents and Chemotherapy. 2009; 53(12): 5046-54.

41. Abdelaziz MO, Bonura C, Aleo A, Fasciana T, Mammina C. NDM-1- and OXA-163-producing Klebsiella pneumoniae isolates in Cairo, Egypt, 2012. Journal of Global Antimicrobial Resistance. 2013; 1(4): 213-5.

42. Zafer MM, Amin M, El Mahallawy H, Ashour MSE-D, Al Agamy M. First report of NDM-1-producing Pseudomonas aeruginosa in Egypt. International Journal of Infectious Diseases. 2014; 29: 80-1.

43. El-Sayed MAE-G, Amin MA, Tawakol WM, Loucif L, Bakour S, Rolain J-M. High prevalence of blaNDM-1 carbapenemase-encoding gene and 16SrRNA armA Methyltransferase among Acinetobacter baumannii clinical isolates, Egypt. Antimicrobial Agents and Chemotherapy. 2015: AAC. 04412-14.

44. Khalil MA, Elgaml A, El-Mowafy M. Emergence of multidrug-resistant New Delhi metallo- $\beta$-lactamase-1-producing Klebsiella pneumoniae in Egypt. Microbial Drug Resistance. 2017; 23(4): 480-7.

45. Barwa R, Shaaban M. Molecular Characterization of Klebsiella pneumoniae Clinical Isolates with Elevated Resistance to Carbapenems. The Open Microbiology Journal. 2017; 11: 152-9.

46. Abdulall AK, Tawfick MM, El Manakhly AR, El Kholy A. Carbapenem-resistant Gram-negative bacteria associated with catheter-related bloodstream infections in three intensive care units in Egypt. European Journal of Clinical Microbiology \& Infectious Diseases: official publication of the European Society of Clinical Microbiology. 2018; 37(9): 1647-52.
47. Hosseinzadeh Z, Ebrahim-Saraie HS, Sarvari J, Mardaneh J, Dehghani B, Rokni-Hosseini SMH, et al. Emerge of blaNDM-1 and blaOXA-48-like harboring carbapenem-resistant Klebsiella pneumoniae isolates from hospitalized patients in southwestern Iran. Journal of the Chinese Medical Association. 2018; 81(6): 536-40.

48. Ahmad N, Ali SM, Khan AU. Molecular characterization of novel sequence type of carbapenem-resistant New Delhi metallo-beta-lactamase-1-producing Klebsiella pneumoniae in the neonatal intensive care unit of an Indian hospital. International Journal of Antimicrobial Agents. 2019; 53(4): 525-9.

49. Stewardson AJ, Marimuthu K, Sengupta S, Allignol A, El-Bouseary M, Carvalho MJ, et al. Effect of carbapenem resistance on outcomes of bloodstream infection caused by Enterobacteriaceae in low-income and middle-income countries (PANORAMA): a multinational prospective cohort study. The Lancet Infectious Diseases. 2019; 19(6): 601-10.

50. Poirel L, Héritier C, Tolün V, Nordmann P. Emergence of oxacillinase-mediated resistance to imipenem in Klebsiella pneumoniae. Antimicrobial Agents and Chemotherapy. 2004; 48(1): 15-22.

51. Arabaghian H, Salloum T, Alousi S, Panossian B, Araj GF, Tokajian S. Molecular Characterization of Carbapenem Resistant Klebsiella pneumoniae and Klebsiella quasipneumoniae Isolated from Lebanon. Scientific Reports. 2019; 9(1): 531.

52. Laolerd W, Akeda Y, Preeyanon L, Ratthawongjirakul P, Santanirand P. Carbapenemase-Producing Carbapenem-Resistant Enterobacteriaceae from Bangkok, Thailand, and Their Detection by the Carba NP and Modified Carbapenem Inactivation Method Tests. Microbial Drug Resistance. 2018; 24(7): 1006-11. 